\title{
DEN-3 no Distrito Federal, Brasil
}

\author{
Teixeira, $J M S^{1}$; Souza, $\mathrm{JL}^{2}$; Silva, $H P^{2}$ \\ Silva, LMP ${ }^{4}$; Cortez, SMFC ${ }^{4}$; Jaime, $\mathrm{MLF}^{4}$ \\ Boçon, $\mathrm{SS}^{4}$; Braga, $\mathrm{KL}^{2}$; Molez, $\mathrm{JF}^{3}$ \\ Degallier, $N^{3}$; Carneiro, $L_{L}^{5}$; Chaib, AJM ${ }^{1}$
}

\begin{abstract}
RESUMO - O Dengue tornou-se problema nacional de saúde pública depois da epidemia causada pelo sorotipo DEN-1, ocorrida em 1986, no Estado do Rio de Janeiro. Em 1990, o DEN-2 foi introduzido no Rio de Janeiro e, atualmente, a circulação de ambos os sorotipos já foi confirmada na maioria dos estados do Brasil, incluindo o Distrito Federal. Em janeiro de 2001, um paciente morador do Rio de Janeiro foi identificado como o primeiro caso autóctone de dengue pelo sorotipo DEN-3, no país. Durante os primeiros quatro meses do ano de 2002, o Laboratório Central de Saúde Pública de Distrito Federal (LACENDF) isolou o sorotipo DEN-3 em amostras de seis casos suspeitos, cinco dos quais importados do estado do Rio de Janeiro e um do estado da Bahia. Em 2003, entre fevereiro e março o vírus foi isolado de cinco casos autóctones. Os isolamentos virais foram feitos em cultura de células C6/36 inoculadas com sangue total, coletado entre o primeiro e quinto dias após o início dos sintomas. Os vírus foram tipados como DEN-3 pela técnica de imunofluorescência indireta usando anticorpos monoclonais sorotipos específicos. Os RNAs virais foram extraídos do sangue total dos pacientes utilizando-se o método de extração por Trizol. Segmentos de DNA de 290 bp foram detectados pelo método de "nested RT-PCR" segundo Lanciott et al (1992), confirmando a prévia identificação dos sorotipos. A introdução do DEN-3 no Distrito Federal representa séria ameaça, uma vez que a maioria das pessoas são suscetíveis a esse sorotipo e muitas já foram infectadas pelos sorotipos $1 \mathrm{e} 2$, aumentando o risco de epidemias e de formas mais severas da doença. $\mathrm{O}$ emprego de método rápido e seguro para o contínuo monitoramento da circulação desses sorotipos é de importância vital para a prevenção e o controle de futuras epidemias.
\end{abstract}

Palavras-chave: dengue, DEN-3, caso autóctone, isolamento viral, RT-PCR

${ }^{1}$ LACEN-DF/UNICEUB; ${ }^{2}$ LACEN-DF; ${ }^{3}$ IRD-UR034; ${ }^{4}$ DIVEP/SES-DF; ${ }^{5}$ UNICEUB Finantial support: FUNASA; LACEN-DF; IRD 


\title{
DEN-3 in Federal District, Brazil
}

\begin{abstract}
Dengue infection became a national public health problem after a DEN-1 epidemic occurred in 1986 in Rio de Janeiro State. In 1990 DEN-2 was introduced into Rio de Janeiro and today the circulation of both serotypes is confirmed in most of states of Brazil, including the Federal District. In January 2001, DEN-3 was first isolated in the country from an autochtonous case, living in the State of Rio de Janeiro. During the first four months of 2002, the survey laboratory of the Federal District (LACEN) isolated six strains of dengue virus serotype 3, five of them from cases imported from Rio de Janeiro State and one from Bahia State. In 2003, between february and march, the vírus was isolated from five autochtonous cases. The virus isolations were performed in C6/36 cell culture inoculated with total blood collected between the $1^{\text {st }}$ and the $5^{\text {th }}$ days after the onset of the symptoms. The strains were typed as DEN-3 by indirect immunofluorescence assay using serotype- specific monoclonal antibodies. Viral RNAs were extracted from total blood using the trizol method. The nested RT PCR method of Lanciott et al. (1992) detected DNA products of $290 \mathrm{bp}$, confirming the previous serotypes identifications. The introduction of DEN-3 in the Federal District represents a serious threat, since most people are susceptible to this serotype and many have already been infected by serotypes 1 or 2 , thus increasing the risk of epidemic of the more severe forms of the disease. The use of a fast and reliable method for continuous monitoring of the circulation of this serotype is of primary importance for the prevention and control of future epidemics.
\end{abstract}

Key words: dengue, DEN-3, autocthonous case, virus isolation, RT -PCR

O dengue é considerado uns dos mais importantes problemas de saúde pública do mundo, na atualidade (GARCIA et al., 1996). A doença é causada pelo Dengue vírus, membro do gênero Flavivirus, família Flaviviridae, que apresenta quatro sorotipos antigenicamente distintos, designados DEN-1, 2, 3 e 4 (NOGUEIRA et al., 2000). A infecção, transmitida principalmente pelo vetor Aedes aegypti, não confere proteção ao indivíduo contra uma segunda infecção por outro sorotipo (ROCCO et al., 2001; TAUIL, 2001).

O Ae. aegypti foi eliminado da maioria dos países americanos nas décadas de 1950 e 1960, como resultado de campanha da Organização Panamericana de Saúde que visava prevenir a febre amarela urbana no continente. Entretanto, em algumas ilhas do Caribe, ocorreram epidemias de dengue durante esse período (DÉGALLIER et al., 2000). No Brasil o Ae. aegypti foi detectado nos Estados 
da Bahia e do Rio de Janeiro nos anos de 1975 e 1977, respectivamente (SCHATZMAYR, 2000). O isolamento dos sorotipos DEN-1 e 4 em 1981, em um surto na cidade de Boa Vista, Roraima, marcou a reintrodução do dengue vírus no Brasil (OSANAI et al., 1983). Entretanto, somente após a epidemia ocorrida no Rio de Janeiro em 1986, causada pelo DEN-1 e sua dispersão para outros estados do país, o dengue tornou-se problema de saúde pública nacional. A introdução do DEN-2 em 1990 no Rio de Janeiro, somada à falta de um programa nacional de controle do vetor, facilitou a rápida dispersão do vírus e o surgimento de epidemias em vários Estados (NOGUEIRA et al., 2000). O sorotipo DEN-3 foi isolado pela primeira vez no Brasil em 1998, em São Paulo, de um paciente com história de viagem recente à Nicarágua (ROCCO et al., 2001). Entretanto, o primeiro caso autóctone causado por esse sorotipo só foi notificado em janeiro de 2001, de uma paciente do sexo feminino, residente no município de Nova Iguaçu, Rio de Janeiro que apresentava sinais e sintomas da febre clássica do dengue (NOGUEIRA et al., 2001). Neste mesmo município, o DEN-3 foi isolado de três pools de Ae. aegypti, coletados entre os meses abril e maio de 2001, confirmando a transmissão desse sorotipo no Rio (OLIVEIRA et al., 2000).

O Laboratório Central de Saúde Pública do Distrito Federal iniciou a vigilância laboratorial de dengue na região, em janeiro de 1991. Naquele ano, foram diagnosticados 29 casos de dengue e foi isolado o DEN-2 de nove amostras, oito de pacientes que estiveram no Rio de Janeiro e uma de origem desconhecida (PIRES et al., 1991). Somente entre janeiro e abril de 1997, foram registrados os primeiros casos autóctones de dengue no Distrito Federal. Em abril de 1998, o DEN-1 foi isolado pela primeira vez de fêmeas de Aedes aegypti, confirmando a transmissão nesta região (DÉGALLIER et al., 2000). A partir do ano de 1997, ambos os sorotipos DEN-1 e DEN-2 vêm sendo isolados de casos autóctones, o que evidencia a circulação de ambos os sorotipos, apesar da significativa predominância do DEN-1 nesses últimos anos.

O presente trabalho relata o isolamento e a caracterização do sorotipo DEN3 no Distrito Federal nos anos de 2002, quando foram detectados os primeiros casos importados, e de 2003, quando foram identificados os primeiros casos autóctones de dengue causados por esse sorotipo.

\section{Materiais e Métodos}

O LACEN-DF recebe amostras de sangue de casos suspeitos de dengue, provenientes de 72 unidades públicas de saúde, além de 8 unidades privadas do Distrito Federal. As amostras destinadas ao isolamento viral são colhidas até o $5^{\circ}$ dia após o início dos sintomas, sem anticoagulante, em criotubos com capa- 
cidade para 1,5 ml, e enviadas imediatamente ao laboratório em caixas isotérmicas com gelo reciclável, congeladas a $-70^{\circ} \mathrm{C}$ até serem processadas.

A células de Aedes albopictus, clone C6/36 (IGARASHI, 1978) são mantidas rotineiramente em meio de cultura Leibovitz L-15(Gibco BRL, Life Technologies) com $10 \%$ de soro fetal bovino (SFB), por meio de repiques semanais, em garrafas descartáveis, estéreis, com área de crescimento de $25 \mathrm{~cm}^{2}$. Para a tentativa de isolamento de dengue vírus, as células são cultivadas em placas para cultura celular, descartáveis estéreis com 96 poços, em volume de 100 ul de meio L-15 com SFB $10 \%$ por poço. Após 48 horas de incubação a $28^{\circ} \mathrm{C}$ e constatada a formação da monocamada celular, o meio L-15 de cada poço é trocado por outro de manutenção, com $2 \%$ de SFB. Alíquotas de 5 ul de sangue total de cada paciente suspeito são inoculadas nos poços contendo as células, sendo utilizados dois poços para cada paciente. Após 7 dias de incubação a temperatura ambiente, as células são raspadas do fundo das placas juntamente com o meio de manutenção, colocadas em lâminas de vidro para imunoflorescência e fixadas com acetona a frio, por 10 minutos. Todas as culturas são examinadas pela técnica de imunofluorescência indireta com o emprego de soro imune polivalente, capaz de reagir com os quatro sorotipos de dengue, produzido e fornecido pelo Centro de Referência Nacional para Dengue, Instituto Evandro Chagas, Belém do Pará, Brasil. As culturas positivas são, posteriormente, submetidas a técnica de imunofluorescência com anticorpos monoclonais sorotipo específicos para a determinação do sorotipo de dengue vírus (GUBLER et al., 1984).

As confirmações dos isolamentos positivos para DEN-3 foram feitas pela técnica de RT-PCR (reverse polymerase chain reaction) conduzida segundo Lanciotti et al. (1992). As extrações dos RNA virais foram feitas com Trizol LS (Gibco) baseada nas mesmas amostras de sangue total usadas para o isolamento viral.

A Diretoria de Vigilância Epidemiológica (DIVEP) da Secretaria de Saúde do Distrito Federal diante de caso suspeito de dengue, realiza visita domiciliar, ao local de trabalho ou à área de lazer freqüentada pelo caso suspeito. Informa a ocorrência dos casos à Diretoria de Vigilância Ambiental (DIVAL) que, juntamente com a equipe formada por agentes de saúde, trabalha com o objetivo de detectar a presença de larvas ou o vetor adulto para ações de bloqueio. Concomitantemente, técnicos da DIVEP entrevistam o suspeito utilizando como instrumento a ficha de investigação epidemiológica do Ministério da Saúde. Diante dos resultados das visitas e de laboratórios e dos deslocamentos realizados pelos pacientes nos últimos 15 dias que antecederam a data de início dos sintomas, são feitas a análise e a definição do Local Provável de Infecção - LPI. Considera-se autóctone a infecção ocorrida no Distrito Federal e importados os casos em que a infecção ocorreu em outra unidade federada. 


\section{Resultados}

Entre janeiro e abril de 2002, período chuvoso no Distrito Federal (DF), foram colhidas e encaminhadas ao LACEN-DF 2238 amostras de sangue para tentativa de isolamento de dengue vírus. Cento e dezesseis $(5,8 \%)$ foram positivas, das quais $105(90,51 \%)$ confirmadas como DEN-1, cinco $(4,31 \%)$ como DEN2 e seis como DEN-3 (5,17\%). Neste período, somente o DEN-1 foi isolado de casos autóctones. Os pacientes com isolamento positivo para DEN-3 eram de ambos os sexos, com idades entre 26 e 59 anos, e todos tinham história de saída recente do Distrito Federal.

No ano de 2003, até a $36^{\mathrm{a}}$ semana epidemiológica, o LACEN-DF recebeu 481 amostras sanguíneas procedentes da rede hospitalar do Distrito Federal acompanhadas das respectivas requisições para isolamento de dengue vírus. Dezesseis delas foram positivas, das quais, seis $(37,5 \%)$ confirmadas como DEN-1 e dez $(62,5 \%)$, como DEN-3. Cinco casos positivos para DEN-3 foram considerados autóctones uma vez que os pacientes não tinham história de saída recente do Distrito Federal (Tabela 1).

Tabela 1. Casos positivos para DEN-3 atendidos na rede hospitalar do Distrito Federal, no ano de 2003.

\begin{tabular}{ccccc}
\hline No. do caso & Início dos sintomas & Data de coleta & Local de residência & Município/Infecção \\
\hline 1 & 20.01 .03 & 22.01 .03 & Samambaia-DF & Palmas-TO \\
$2^{*}$ & 15.02 .03 & 18.02 .03 & Guará-DF & Distrito Federal \\
3 & 19.02 .03 & 19.02 .03 & Paranoá-DF & Luziânia-GO \\
4 & 03.02 .03 & 05.02 .03 & Luziânia-GO & Luziânia-GO \\
$5^{*}$ & 03.02 .03 & 05.02 .03 & Paranoá-DF & Distrito Federal \\
$6^{*}$ & 25.02 .03 & 25.02 .03 & São Sebastião-DF & Distrito Federal \\
$7 *$ & 21.02 .03 & 25.02 .03 & São Sebastião-DF & Distrito Federal \\
8 & 11.02 .03 & 13.02 .03 & Paranoá-DF & Bahia \\
$9 *$ & 05.03 .03 & 10.03 .03 & Paranoá-DF & Distrito Federal \\
10 & 26.03 .03 & 28.03 .03 & Luziânia-GO & Luziânia-GO \\
\hline
\end{tabular}

Nota: Encontram-se destacados os casos autóctones.

Fonte: DIVEP-DF e LACEN-DF 
Por meio do método de nested RT-PCR, segundo Lanciott et al. (1992), foi possível detectar produtos de DNA de 290 bp nas amostras sanguíneas dos pacientes com isolamento positivos para DEN-3, analisadas nos anos de $2002 \mathrm{e}$ 2003. Isto confirma o resultado da tipagem com anticorpos monoclonais (Figura $1)$.

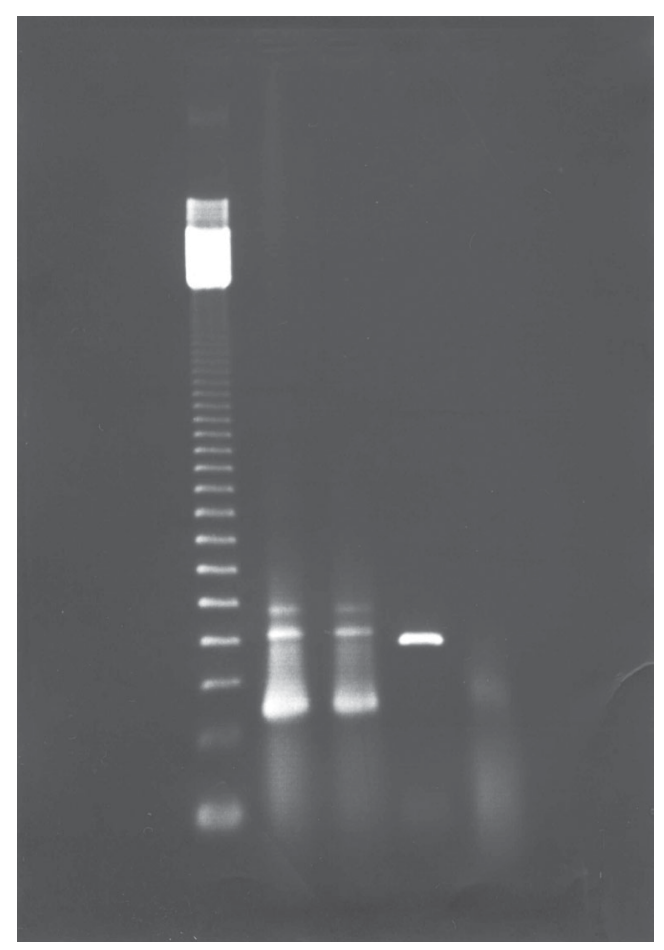

Figura 1 - Caracterização do sorotipo DEN-3 através da reverse transcriptasechain reaction (RT-PCR). Gel de agarose corado pelo brometo de etidium. Colunas 1: marcador de peso molecular 100bp-DNA leader (Gibco). Colunas 2 e 3: Produtos do RT-PCR correspondendo a 290 bp obtidos de duas amostras sanguíneas com isolamento positivo para DEN-3. Coluna 4: Produtos do RT-PCR correspondendo a 482 bp obtido de uma amostra de sangue total com isolamento positivo para DEN-1. 


\section{Discussão}

A dispersão do DEN-3 em todo o território brasileiro evidenciou a rapidez com que novos sorotipos podem ser disseminados. A propagação do dengue é muito facilitada pela velocidade e grande fluxo dos tráfegos aéreo e terrestre. Rapidamente, o vírus pode ser transportado de uma cidade a outra, de um país a outro e até de um continente a outro, no sangue de indivíduos na fase virêmica (TAUIU, 2001) ou mesmo dentro do vetor. Brasília, pela condição de capital do país e por receber, continuamente, um grande contingente de visitantes de outras unidades da federação e também de outros países, é bastante vulnerável à introdução de novos sorotipos. É sabido que a introdução de novo sorotipo de dengue em população suscetível é sério fator de risco de ocorrência de formas severas da doença (ROCCO et al., 2001). Em estudo realizado na Nicarágua, foi evidenciada a capacidade de o sorotipo DEN-3 produzir epidemias de dengue hemorrágico quando associado a grande número de pessoas suscetíveis e altas densidades do vetor, situação compartilhada pela maioria dos países do continente americano (GUZMÁN et al., 1996).

A caracterização molecular do DEN-3 isolado do primeiro caso autóctone do Brasil no Rio de Janeiro mostrou que este vírus pertence ao mesmo genotipo das cepas de DEN-3 que circulam no continente americano e reforçou a tese de que o Rio de Janeiro é importante ponto de entrada e dispersão do dengue vírus no Brasil (OLIVEIRA et al., 2002).

Os achados de 2002 no Distrito Federal são compatíveis com essa tese, uma vez que, dos seis pacientes nos quais o DEN-3 foi isolado, cinco haviam voltado recentemente das férias de verão na cidade do Rio de Janeiro.

A caracterização dos primeiros casos autóctones de DEN-3 em 2003 no Distrito Federal é bastante preocupante uma vez que a população é suscetível a este sorotipo, e muitos já foram infectados pelos sorotipos 1 e 2 , o que representa sério fator de risco de ocorrência de epidemias e formas severas da doença. Diante desse cenário, faz-se necessária a vigilância epidemiológica eficiente que possa detectar, precocemente, a circulação e a eventual transmissão de novos sorotipos e desencadear ações que possam reduzir o impacto do dengue em nossa região. Julgamos ser pertinente o estudo das possíveis variações genotípicas intrasorotípicas dos DEN-3 isolados em nossa região e dessa forma gerar dados sobre a origem desses vírus e também sobre as relações entre genótipo e virulência. 


\section{Referências}

Degallier, N. et alli. "First isolation of dengue vírus 1 from Aedes aegypti in Federal District, Brazil”. In: Revista da Sociedade Brasileira de Medicina Tropical. 33(1):95-96, 2000.

Garcia, B.B. et alli. "Potencial risk for dengue hemorragic fever: the isolation of serotype Dengue 3 in México". In: Emerging Infectious Deseases. 2(2):133-135, 1996.

Gubler D.J et alli. "Mosquito cell cultures and monoclonal antibodies in surveillace for dengue viruses”. In: J Trop Med Hyg 33: 158-165, 1984.

Guzmán, M.G et alli. "Dengue en Nicaragua, 1994: reintroducion do sorotipo 3 en las Américas”.In: Bol. Oficina Sanitaria Panamericana. 121(2), 1996.

Igarashi, A.'Isolation of a Singh's Aedes albopictus cell clone sensitive to dengue and chikungunya viruses". In:. J. Gen. Virol. 40: 531-544, 1978.

Lanciotti, R.S. et alli. "A rapid detection and typing of dengue viruses from clinical samples by using reverse transcriptase polimerase chain reaction". In: J. Clin. Microbiol. 30: 545-555, 1992.

Nogueira, R.M., et alli. "Dengue viruses type 3 in Rio de Janeiro, Brazil”. In: Memórias do Instituto Oswaldo Cruz. 96(7): 925-926, 2001.

Nogueira, R.M.R.; Miagostovich, M.P. \& Schatzmayr, H.G. "Molecular epidemiology of DEN-2 viruses in Brazil". In: Caderno de Saúde Pública. Rio de Janeiro. 16(1): 205-211, 2000.

Oliveira, R.L. et alli. "Dengue Vírus Type 3 Isolation from Aedes aegypti in the Municipality of Nova Iguaçu, State of Rio de Janeiro”. In: Mem. Inst. Oswaldo Cruz. 97(6):799-800, 2002.

Osanai, C.H.; Travassos da Rosa, A.P.A. \& Tang, A.T. "Surto de Dengue em Boa Vista, Roraima”. In: Revista do Instituto de Medicina Tropical de São Paulo. 25: 5354, 1983.

Pires, M.F.C. et alli. "Invetigation on dengue in Distrito Federal, Brazil". In: Resumos Virológica 91: II Simpósio Internatonal Sobre Arbovirus dos Trópicos e Febres Hemorrágicas. Belém, PA, 1991. p.2.

Rocco, M.I.; Kavakama, B.B. \& Santos, C.L.S. "First isolation of Dengue 3 in Brasil from a imported case". In: Revista do Instituto de Medicina Tropical de São Paulo. 43(1):55-57, 2001.

Schatzmayr H.G. "Dengue situation in Brazil by year 2000”. In: Memórias do Instituto Oswaldo Cruz. 95(Suppl I) 179-181, 2000.

Tauil, P.L. "Urbanization and Dengue Ecology”. In: Cad. Saúde Pública. 17(Suppl): 16, 2001. 